\title{
Tiempo líquido: la crisis del libro y la lectura
}

\author{
HÉctor Guillermo Alfaro López \\ Centro Universitario de Investigaciones Bibliotecológicas \\ de la UNAM, 04510, México D .F., Tel: (525)623-03-58 \\ E-mail: galfaro@ servidor.unam.mx
}

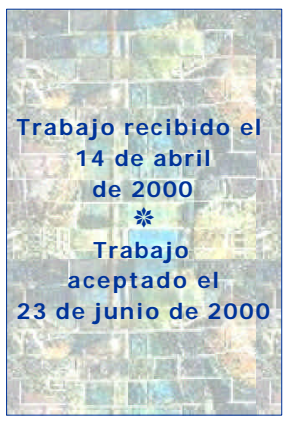

RESUMEN

A través de la crítica a la obra de Marshall McLuhan se explica cómo el siglo XX representa un punto de inflexión en la historia de 0 ccidente, porque es una centuria en la que se dio el privilegiamiento de la forma sobre el contenido, como quedó codificado en el eslogan mcluhano: el medio es el mensaje; lo cual se hizo evidente con el desarrollo de los medios electrónicos de información. Esta situación repercutió en la crisis de la producción del libro y la práctica de la lectura, sujetas ahora a una nueva temporalidad, que denomino tiempo líquido. Crisis entendida no como punto final sino etimológicamente como "punto decisivo", a partir del cual se perfilauna nueva trayectoria del libro y de la lectura.

Palabras clave: Lectura; McLuhan, Herber Marshall; Libro.

\section{LIQUID TIME. BOOKS AND READING IN CRISIS HÉctor Guillermo Alfaro-López}

\section{ABSTRACT}

The present study explains, through a critical approach to the work of Marshall McLuhan, the ways in which the XX century represents a point of inflection in the history of the West, because, characteristically, in this century form has taken precedence over content as expressed in McLuhan's adage "the medium is the message"; this is especially evident with the development of the electronic media. This situation has had repercussions in the crisis of books and reading, which are subjected now to a new temporality which I call liquid time. The crisis alluded to should be understood not as an end, but rather in its etymological rootas "turning point" from which a new trajectory for books and reading may be seen.

Key Words: Reading; McLuhan, Herber Marshall; Book. 
ت1

lmedioesd mensaje el famoso eslogan de Marshall McLuhan marcó las últimas décadas del siglo XX, su sentido fue debatido con vehemencia; quienes lo atacaron, en el mejor de los casos, sólo lo consideraron un excelso logro de la banalidad, mientras que por el contrario sus defensores vieron en él una verdad incuestionable y, en cuanto tal, fue invocado como si se tratara de un mantra. Pero de tanto repetirse el eslogan terminó por vaciarse de contenido para mimetizarse con el formalismo que postula, y por un equívoco camino adquirió veracidad: laforma predomina sobre el contenido, y en esto no subyacen los subterfugios de la paradoja sino la claridad de una lógica (por supuesto formal). Para los seguidores de McLuhan esto sólo vendría a ratificar la verdad enunciada en el eslogan, la cual cuenta además con la puntual complicidad de la realidad social contemporánea, en la que los medios tecnológicos han reducido el contenido del mensaje a una decorosa función de comparsa. Más aún, los no escasos tecnólogos acólitos de McLuhan ven en esa complicidad dela realidad el cumplimiento de la profecía que se anuncia en la verdad del eslogan, el advenimiento de la sociedad tecnificada, es decir, de la sofisticada aldea global. Todo lo cual confirma a Marshall McLuhan como el profeta de la tecnología del siglo XX, atuendo que él mismo vistió con heróica satisfacción.

En versión canónica: a través de los profetas $\mathrm{D}$ ios conduce alos hombres por el recto camino que lleva a la felicidad en este mundo y en el otro, prometiendo la dicha a los buenos y amenazando con terribles castigos a los malos. En versión apócrifa: la tecnología, elevada a deidad, se deja escuchar a través del profeta McLuhan para conducir a los hombres del siglo XX por el camino que conduce en este mundo hacia la aldea global, prometiendo la dicha a todos aquellos evadidos de la galaxia de Gutenberg y amenazando con terrible castigo a los irredentos hombres tipográficos. Lo anterior nos lleva a plantearnos cuál es el carácter y la función del profeta dentro de una sociedad. De ninguna manera el profeta es un adivino, no describe el futuro sino que anuncia una posibilidad revestida por la esperanza, de modo que ese anuncio más que una visión es un acto de fe; sin embargo, la posibilidad que anuncia el profeta está anclada en el contexto desde el cual se emitió. He aquí la otra característica del profeta, a la par de ser mediador divino, es un individuo marcado por su época y su medio original, al grado de que su mensaje refleja características esenciales de su circunstancia y su tiempo histórico; por lo mismo, lo que anuncia no es lo que sucederá en el futuro sino la proyección de su presente en el futuro, considerado como lo mejor que tiene. La esperanza surge a partir del anhelo de que en el porvenir se realice la mejor parte del presente, y de que esté libre de lo negativo. D e hecho esto es lo que en el fondo le da relieve e importancia a la figura del profeta y de su mensaje: son paradigmáticos de su tiempo. 
El mensaje del profeta dice más sobre el contexto de éste, que sobre el porvenir. Por esta razón es importantela obra de Marshall McLuhan, dice más del siglo XX que de la futura sociedad que profetizó.1

Para orgullo de McLuhan su obra ha sido y es un atrayente territorio sin ley, donde la violencia interpretativa de los críticos encuentra grato cumplimiento; así, por ejemplo, el gurú de la crítica G eorge Steiner sentencia: “Sería fácil hacer la anatomía de LagalaxiadeGutenbergde esta forma: un libro fácil y estúpido (...) es un antilibro."2 Pero aun por sobre estas antivirtudes (o precisamente por ellas) Steiner concluye quevale la pena adentrarse en la mosaical obra del profeta. O tra crítica no menos bizarra, de JamesJ. O 'D onnell, concluye que: "En resumen, dos cosas sobre McLuhan: su obra resulta muy valiosa, pero no por lo que pudiera parecer. Resultainstructiva, estimulante y enloquecedora, más eficaz cuanto más enloquecedora. Pero sus profecías no conducen a aplicaciones prácticas. Si se juzgan como mitos, son muy buenos, si se juzgan como historia o sociología no lo son tanto." 3 Esto último amerita enmarcarse, sus profecías ascendidas al rango de mitos alcanzan reconocimiento, mientras que estimadas como historia o sociología tienen como premio de consolación el olvido. Por ello puede decirse que la obra de McLuhan es un gran mito donde tienen resonancia privilegiada las fuerzas, tensiones y trayectorias forjadoras del siglo XX. Centuria que, sin ánimo hiperbólico, bien puede ser caracterizada como la del triunfo de laforma yla desintegración del contenido: el medio es el mensaje. Esto como punto culminante de un largo y complejo proceso civilizatorio occidental, entre cuyas líneas centrales configuradoras se encuentran el libro y la lectura.

El siglo XX es un punto de inflexión en la historia de O ccidente, ahora que ha quedado a nuestra espalda comenzamos a tener la distancia que nos permite comprender su significación como un momento determinante y de cambio en relación con la trayectoria previa seguida por las sociedades occidentales (y de hecho del mundo) desde los inicios de la modernidad. Punto de inflexión que alcanza peculiar evidencia al seguiry basarse en el desenvolvimiento del libro y la lectura. Tal evidencia queda claramente dibujada en la "enloquecedora obra" de McLuhan. Así pues, su obra es un umbral idóneo para acceder a la problemática del libro y la lectura durantela pasada centuria, lo que de paso nos permite vislumbrar, sin aspiración profética, la trayectoria que seguirán éstos en el siglo siguiente.

1 "Primero, profetizar es un juego de rufianes. Eneas se lo podía haber dicho a McLuhan. Él había visto todo el futuro de Roma ante él en su visita al submundo, pero lo que viera allí le ayudó muy poco en su vida. Los profetas de Israel nunca acertaban al predecir el comportamiento de su pueblo. La profecíareflejaun estilo de decir la verdad que garantiza su incredulidad. (Los profetas también se equivocan, al igual que McLuhan, y eso no habla en su favor, pero todod mmdbse equivoca, y eso no nos despoja de toda credibilidad)". James J. O 'D onnell, "La pragmática de lo nuevo: Tritemio, McLuhan, Casiodoro" en Nunberg, G eoffrey (comp.), El futuro dd libro ¿Estomatará œo?, Barcelona, Paidós, 1998, p. 55.

2 G. Steiner, "Leer a McLuhan" en Lengrajeysilenia Ensayosdarelaliteratura, d lenguajeyloinhumano México, Gedisa, 1990, p. 239.

3 J. O’D onnell, qp at, pp. 56-57. 
Crucemos una vez más la misma puerta: themediumis themessage el eslogan de McLuhan es el mascarón de proa de todo su pensamiento, en él se dan cita los temas que lo obsesionaron y le dieron la certidumbre de su destino como profeta. ${ }^{4} \mathrm{D}$ e ma nera compendiosa trata de decir que el medio ejerce efectivamente un efecto sobre y por encima del contenido del mensaje mismo. Así, el efecto que causa en el receptor una comunicación no depende de las ideas, los mensajes o la información, sino del medio de comunicación empleado. Es una reivindicación de lo formal frenteal contenido, que incluso eleva la forma a ley interna del medio. Esta sencilla idea que apa rentemente parece sólo dar fe de un fenómeno cotidiano dentro de una sociedad tecnificada, comienza a tornarse compleja cuando McLuhan la articula con el aparato sensorial humano. Resulta una aguda intuición concebir los medios como una extensión real de los sentidos; lo que redunda en una visión del desarrollo tecnológico como meelio que logra una prolongación de la corporalidad. Y es aquí donde McLuhan introduce la historia; los medios cambian, evolucionan alo largo del tiempo, y esto conlleva cambios en la forma de ver el mundo así como en la organización social. Ahora bien, esos cambios están signados por el tránsito de lo que él define como el mødocalientehacia el mediofí́ El hdmædumprolonga un solo sentido: la vista, que produce la segmentación de los demás sentidos. La vista se distingue por su alta definición, porque produce mensajes lineales y claros, datos e informaciones precisos; sus medios característicos y definitorios son la escritura y la imprenta, propios de los que famosamente definió como la GalaxiaGutenberg Por el contrario, el cod meelumextiende todos los sentidos y con ello los unifica; es de baja definición, puesto que sus mensajes se dan más como proceso que como producto acabado, y más de forma simultánea y plural antes que lineal; es el medio par excellenede la era electrónica. En el momento en que McLuhan hace tal definición, la década del 60, el medio frío más difundido es la televisión, por lo que no le escatima el ditirambo que la considera como el medio de comunicación liberador de los rezagos del hotmedum y, por consiguiente, de la galaxia de G utenberg. La televisión produce un espíritu antitético al del alfabetismo y, por fortuna no sólo eso, además al unificar todos los sentidos en una simultaneidad los hunde en un vertiginoso estado alucinatorio, que prefigura el estado estupefaciente producido por la computadora, como se detallará más adelante. A partir de este punto las ideas de McLuhan empiezan a adquirir la grandilocuencia profética y, por ende, su transfiguración en mito. Su visión de la

4 Isaiah Berlin en zoológica clasificación dividía a los pensadores en: zorros y erizos. Los primeros son aquellos que tienen la capacidad de producir, cambiar y aceptar múltiples ideas a lo largo de su trayectoria intelectual; mientras que los pensadores erizos son aquellos que giran permanentemente en torno a un breve núcleo de ideas, digamos que son los que se casan para siempre con una sola idea. A esta clase de fieles pensadores pertenecía McLuhan, era un celoso erizo. El breve núcleo de sus ideas está expuesto de manera completa en su primer libro importante La galaxia Gutenbag el notorio aporte de sus obras posteriores consistió en exacerbar el ingenio para decir lo mismo de distinta manera. Por ello, para comprender sus ideas es necesario en primera (y hasta última) instancia remitirse a Lagalaxia Gutenberg aunque antes hay que pasar por la prueba de fuego de recomponer su dislocada argumentación, que él con alegre estrategia discursiva definió como, de mosaico. 
historia asume la dimensión mítica cuando divide a ésta, con base en el desenvolvimiento tecnológico, como medio calientey medio frío, esto es, en la era de la galaxia G utenberg y la que sucede a ésta, la era electrónica. Un largo ciclo histórico que termina con la extinción de la galaxia Gutenberg, mientras que la aurora de la nueva época histórica anuncia la salvación humana.

Ahora bien, la parte fuerte del mito consiste en una concepción del hombre y sus procesos vitales a partir de un medio y un objeto, lo cual ha dado lugar a una civilización de características desintegradoras y deshumanizadoras. Es el homotypogaphiaus, cuya experiencia vital está regida por el sentido visual a través de la lectura, el hotme dumque determina esto es la imprenta que produce el objeto libro, y todo ello ha dado como resultado la enajenante civilización moderna occidental.

El hombre primitivo que antecedió al hombre tipográfico vivía en el paraíso del intercambio oral, pero su caída en el pecado sedio cuando inventó el alfabeto y la escritura, tuvo entonces que abandonar su idílica aldea e iniciar su estigmatizada peregrinación a lo largo de la historia para ganarse el derecho a retornar a la aldea. El estigma consistió en que tuvo que depender en demasía de su vista, a expensas de los demás canales sensoriales. Mas lo peor vino cuando fijó la escritura con los tipos de la imprenta - había que tocar fondo en el descenso pecaminoso- y su castigo fue la transfiguración en el hombre tipográfico, que al quedar subyugado por la tecnología industrial de la imprenta es conducido a la deshumanización de la vida mecánica; este hombre se somete sin protesta al castigo de una vida repetitiva. La regularidad lineal de la página impresa lo obliga a aceptar ideas que obedecen a determinados modelos lógicos, y su sentido de la comunidad espiritual va disminuyendo paralelamente con el aumento de su maestría técnica. Pero después de siglos de cargar el estigma, dibujado en su vista, del pecado tipográfico, comienza a vislumbrar el camino de redención que lo conducirá a la retribalización. Ese camino es el del cod meeliumy el profeta que con índice flamígero lo señala es Marshall McLuhan. La tecnología de los medios fríos, al acabar con el universo lineal de la galaxia de $\mathrm{G}$ utenberg, crea las condiciones para la retribalización; esto es, la reconstitución de un medio global semejante al de la aldea primitiva. La humanidad se encamina así al estadio de civilización de la aldea glo bal, donde será redimida tras haber caído en el pecado del alfabeto, la escritura y la tipografía; pero más aún, se dirige ahora hacia el territorio donde los sentidos humanos se reunifican y derrocan al imperio de la vista. En esta aldea primitiva y altamente sofisticada el libro sólo será una exquisita pieza de museo que servirá como recordatorio que evita la tentación de incurrir nuevamente en el pecado tipográfico. Esa tierra prometida comenzó precisamente a perfilarse en el siglo $\mathrm{XX}$, centuria que por tanto constituye el gran escenario donde se representa la caída del homotypogaphiasy el ascenso del hombre de la era electrónica, cuyo destino está signado por los medios fríos que han logrado mejor que todos los anteriores medios convertir la forma en ley que rige por encima del contenido.

En la historia bíblica del devenir tecnológico de McLuhan queda claro que el fruto que provoca la caída en el pecado es la palabra escrita, que al pasar por el medio 
caliente de la imprenta queda cristalizada en la regularidad de las líneas impresas de los libros; pero esta historia culmina con la liberación (o volatilización) de la palabra a través de las imágenes producidas por los medios fríos. La obra de McLuhan refleja ese movimiento de liberación de la palabra que caracterizó el desenvolvimiento del siglo XX lo cual, cabe subrayarse, produjo una reconstrucción dela práctica de la lectura. El siglo XX fue protagonista de lo que Roger Chartier llama la tercera revolución de la lectura desde la Edad Media: la primera revolución señala el tránsito de la letura oral a la lecturasileniosa, la cual es incluso anterior a la revolución sufrida por el libro; la segunda revolución, que aconteció con anterioridad a la industrialización en la fabricación de lo impreso, transita de la lecturaintensiva la lectura extensiva; y la tercera es la más radical de tales revoluciones: "La transmisión electrónica delos textos y las maneras de leer que impone representan, en nuestros días, la tercera revolución sobrevenida desde la Edad Media. Porque, desdeluego, leer en una pantalla no es lo mismo que leer en un códice (...) Por tanto, lo que se halla totalmente transformado es todo el sistema de identificación y de manejo de textos." 5 Esta revolución es anunciada bajo la indumentaria de mito apocalíptico en la obra de McLuhan. La muerte de la galaxia de $G$ utenberg entraña, en primera instancia, el fin de los objetos sólidos del invento del impresor Gutenberg y, por consiguiente, también el de la práctica de la lectura propiciada por el libro impreso. Pero en segunda instancia representa el ocaso de un proyecto civilizatorio que cuenta entre sus soportes fundamentales precisamente con el libro impreso y su correlativa lectura; apocalipsis cuya aura retórica viene aser "el medio es el mensaje". Esto nos plantealas siguientes preguntas ¿A través de qué procesos a lo largo de la historia pero principalmente en el siglo XX, se dio el predominio de la forma so bre el contenido, que encuentra codificación en la obra de McLuhan? ¿Cómo se expresó la supeditación del contenido ala forma en el desenvolvimiento del libro y la lectura, para que McLuhan decretara la extinción de la $\mathrm{G}$ alaxia de Gutenberg, de la que aquellos son parte esencial?

El desarrollo tecnológico occidental alcanza en el siglo XX su más alto nivel de sofisticación con el último giro de tuerca que encarna la tecnología electrónica. Una delaspinipalesvirtudesdelatemdoǵadectrónicao, másespeéficamente, delosmedios deetrónicos( de Marx sobre la tendencia del mercantilismo capitalista a hacer que todo lo sólido se desvanezca en el aire, y que Marshall Berman (siguiendo los supuestos del propio Marx) señaló como lo característico de la experiencia de la modernidad, encuentra su completa realización en la cibernética. La tecnología electrónica representala fase más depurada de la larga historia de la tecnología en la civilización occidental. D esde el Renacimiento el impulso de la ciencia y la técnica dará como resultado que ambas sean fusionadas por el pragmatismo de la racionalidad instrumental y desemboquen en la tecnología; lo que prepara a ésta para ser factor decisivo en los grandes avances

5 Guglielmo Cavallo y Roger Chartier (dirección), Histaria dela letura en d mundbocidental, Madrid, Taurus, 1998, Introducción p. 42. 
científicos, plasmados pragmáticamente en la invención y el perfeccionamiento de las máquinas, ${ }^{6}$ las cuales comenzaron a formar parte del paisaje cotidiano delos individuos y las so ciedades. Cada nueva etapa de desarrollo capitalista da lugar a una etapa de mayor depuración tecnológica, la cual a su vez retroactúa sobre la misma estructura social, y la impulsa hacia nuevos cambios, que asimismo producen novedosas transformaciones en la tecnología. La interacción recursiva organizacional, 7 nuestra condición de productos y productores de los cambios so ciales y tecnológicos, se manifiesta de manera inmediata en cada una de las actividades usuales de la colectividad y de los individuos, lo que hace que su horizonte vital se pueble cada vez más de máquinas. Esto es así hasta llegar a ser la computadora de fines del siglo $\mathrm{XX}$, un utensilio de la vida cotidiana. No obstante estas etapas por las que pasó la tecnología fueron y son acompañadas por configuraciones mentales y formas de articulación de las relaciones entre los individuos. En la medida en que la tecnologíay sus productos adquieren mayor presencia en la vida cotidiana se convierten en un mediador que determina la mentalidad y las relaciones sociales, y con ello los procesos de percepción sensorial de la realidad. Percepción que, por otra parte, suministra la información, que viene a ser la base de los contenidos de la mente. Kant sostuvo que "nada hay en la mente que no haya pasado por los sentidos". Contenidos de la mente que eran fundamento del contenido de los mensajes, y que hasta antes del advenimiento del col medumconstituían la ley interna de la forma: $\mathrm{A}$ conte nidbes d mensaje

Uno de los primeros y decisivos efectos producidos por los medios electrónicos en su camino de predominio sobre los contenidos es la disgregación de los mecanismos de percepción sensorial, que se logra gracias al torrente continuo de información disponible y a la alta velocidad de su transmisión, lo cual hace que la realidad se presente como un todo simultáneo y desintegra al espacio y el tiempo como categorías de la experiencia sensorial concreta. Esto propicia ese estado alucinatorio simultaneísta de la televisión queinfantilmentefascinabaa McLuhan yal queleatribuyó el milagro de reunificar los sentidos: estado estupefaciente que por demás se ahonda con la cibernética. El usuario de la computadora es un viajero inmóvil cuyo vehículo es la luz (en la que se desvanece lo sólido), computadora que le permite vivir pasado, presentey futuro en tiempo real. En el transcurso de su viaje petrificado los sentidos se reunifican, pero pierden la orientación y con ello su potencial de captación y de

6 Véase, Alfaro López, H. G., "El hombre y la técnica” en CuademosAmericanos Nueva Época, No. 62, marzo- abril, 1998.

7 Edgar Morin enuncia tres principios del movimiento de lo real, que son el dialógico, el hologramático y el de recursión organizacional. Éste último lo enuncia de la siguiente manera: "Un proceso recursivo es aquel en el cual los productos y los efectos son, al mismo tiempo, causas y productores de aquello que los produce (...) Esta idea es también válida sociológicamente. La sociedad es producida por las interacciones entre individuos, pero la sociedad una vez producida, retroactúa sobre los individuos y los produce (...) somos, a la vez, productos y productores". Introducciónal pensamier tocompléo Barcelona, G edisa, 1994, pp. 106-107. 
comunicación social. ${ }^{8}$ El medio frío se sobreimprime en la mente del usuario apoderándose de sus contenidos por vía de la estructura de programas que tienen una lógica limitada: el medio es el mensaje. Pero sin los fundamentos de la percepción sensorial no pueden propiciarse la abstracción ni el concepto, lo cual causa la desarticulación del lenguaje y con él la difuminación de la memoria, como lúcidamente lo explica Horst Kurnitzky:

La percepción está mediada por la lengua. La lengua muestra que el mundo percibido no es solamente 'mi mundo'. Todos los otros participan y transmiten a través de la lengua sus experiencias no hay ninguna experiencia sin lengua. Ella quiere la experiencia y, trabajada en lengua, conservarla en la memoria para recurrir a ella. Como las artes, la lengua es un medio para elaborar la memoria, que solamente es recordada como memoria elaborada. La experiencia concreta y sensorial permanece como condición, pues sobre ella se construye toda experiencia y a ella regresa toda la memoria. ${ }^{9}$

Pensamiento, memoriay lengua, que son el contenido (la solidez) de la mente, se deslizan hacia la obsolescencia al imponerles el medio electrónico su ley, por lo que al exteriorizarse sensorialmente pierden gran parte de su capacidad comunicativa. La continuidad discursiva del pensamiento se ve fragmentada y la memoria entra en la oscuridad de la amnesia, al imponérsele el predominio de un presente en el que todos los tiempos se viven de manera simultánea. A semejanza de la discursividad del pensamiento, la memoria se despliega en una sucesión continua que le permite preservar el pasado (lo anterior), para reafirmarlo en el presente (el momento) y poder proyectar el porvenir(lo posterior). Trastocar la sucesión en aras dela simultaneidad conlleva a la par que hacia el dislocamiento de procesos naturales de la mente, hacia la desobjetivación de la vida del individuo, con el consiguiente desajuste de la vida social. La vida de todo ser humano está signada por la finitud, y para llegar precisamente a ese fin último su existencia discurre en la sucesión espacio temporal, a tal sucesión se corresponden la sucesión del pensamiento y la memoria. Y la sucesión de ambos es la que se expresa en el movimiento del lenguaje. Las limitantes propias de la lengua le impiden comunicar la simultaneidad y, más aún, al recibir la mente a través de los medios electrónicos esquemas rudimentarios la lengua se torna balbuceante o sólo apta para el tópico. Lo que hace que la comunicación intelectiva y sensorial propia de, como clamaba Miguel de Unamuno, hombres de "carne y hueso" se obnubile, y deja encaminados a los hombres de la era electrónica hacia la colonización de la aldea global. La vía para llegar directamente a la aldea global es a través

8 "Velocidad absoluta significa inmovilidad; la omnipresencia impide el movimiento. Y la transformación de los objetos sensorialmente perceptibles en imágenes titilantes 0 , por decirlo de otro modo, la transformación de la materia en luz, significa la pérdida de las esenciales capacidades humanas de orientación y, ante todo, la pérdida de comunicación sensorial que es lo que, antes que nada, produce la vida social". Horst Kurnitzky. Vetig்nosainmmilidad Loscambios gddbalesdela vida social, México, Blanco y Negro, 1998, p. 86.

9 Ibid, p. 87. 
del ingreso al espacio virtual, espacio donde los individuos que han quedado desgajados del contenidbsocial quedan bajo laleydelaformaque les impone el medio cibernético. El individuo como portador del mensaje de lo humano (que se realiza en el encuentro sensorial eintelectivo entre hombres de carne y hueso) queda relegado - se desvanece- dentro del medio productor de la globalidad virtual: themedumis the message

Todo esto finalmente viene a significar la inflexión de dos líneas de tensión configuradoras del proyecto civilizatorio occidental que eran entretejidas por el libro y la lectura: el humanismo racionalista y la constitución del espacio público. El Renacimiento es también una inflexión histórica respecto a la trayectoria medieval precedente, cuya misión y aspiraciones quedan codificadas en el discurso humanista. La revalorización del hombre 0 , más exactamente, su divinización entrañaba la creación de su figura a partir de proyectarle atributos que en el medievo se consideraban sólo inherentes a D ios, como son los de autonomía y racionalidad, que desembocaban en una libertad desgajada del designio divino. Lo que incluso provocó el reconocimiento de la corporalidad; el cuerpo ya no era el territorio estigmatizado por el pecado y, en cuanto tal, condenado a la extranjería en el mundo. A hora el cuerpo humano es considerado como un ámbito deplena vivencialidad que no tiene estigma, y que estálegitimado con la posesión de un espacio en el mundo. El Renacimiento entonó el gran canto sobre la dignidad del hombre y el más afinado de sus cantores fue G iovanni Pico D ella Mirandola, cuya partitura fue precisamente su Disarsodeladig nidad da hombre Texto que contiene claramente delineados la visión y el programa del humanismo renacentista, como queda patente desdela exaltación de las palabras iniciales:

(...) el hombre es el intermediario de todas las criaturas, emparentado con las superiores, rey delas inferiores, por la perspicacia de sus sentidos, por la penetración inquisitiva de su razón, por la luz de su inteligencia, intérprete de la naturaleza, cruce de la eternidad estable con el tiempo fluyente y cópula del mundo y como su himeneo, un poco inferior a los ángeles, en palabras de David. Muy grande todo esto ciertamente, pero no lo principal, es decir, que se arrogue el privilegio de excitar con justicia la máxima admiración. ¿Por quéno admirar más a los mismos ángeles y a los beatísimos coros celestiales? A la postre, me parece haber entendido por qué el hombre es el servivo más dichoso, el más digno, por ello de admiración, y cuál es la condición suya que le ha caído en suerte en el conjunto del universo, capaz de despertar la envidia, no sólo de los brutos, sino de los astros, de las mismas inteligencias suprahumanas. Increíble y admirable. Y ¿cómo no, si por esa condición, con todo derecho es apellidado y reconocido el hombre como el gran milagro y animal admirable?10

Muy probablemente a McLuhan las palabras de Pico D e la Mirandola le sonarían como el inicial y más extravagante deliquio del hombre tipográfico, pero lo que queda patente en ellas es la enunciación del humanismo racionalista. El hombre se

10 Pico De la Mirándola. Dela digridaddd hombre, Madrid, Editora Nacional, 1984, pp. 103-104. 
humanizay toma posesión de sí mismo por mediación de la razón: se autoconstruye racionalmente. La razón como fundamento dela autonomíay la libertad del hombre se convirtió en factor decisivo en el desenvolvimiento civilizatorio occidental moderno, a la vez como discurso y como práctica. Disarsoraacnalista que será elaborado y reelaborado por las distintas disciplinas del conocimiento, principalmente la filosofía, y que alcanza con el discurso cartesiano su primera formulación sistemática hasta llegar al discurso contra la razón instrumental enunciado por la Escuela de Frankfurt. Prádica raaionalistaque dirige la actividad individual y colectiva en el proceso de construcción de la realidad social y del dominio sobre la naturaleza. El humanismo racionalista representa la etapa inicial de ese discurso y de esa práctica que estaban dirigidas al autoconocimiento del hombrey a orientar su posesión del mundo. El área cognoscitiva que gradualmente fue convirtiéndose en basamento del discurso y la práctica racionalista fue la físicomatemática, que en el Renacimiento tiene el primer gran despertar. El despliegue racionalista de la civilización occidental sufrió diversas metamorfosisy sedesvió por distintos afluentes, uno de estos, el quesiguió más fielmente el modelo físico matemático, es el que desemboca en el proyecto tecnológico. A hora bien, el vehículo que el Renacimiento utilizó para difundir el humanismo 0, más exactamente, su racionalismo, fue el libro.

En 1501 aparecen por primera vez las famosas ediciones de Aldo Manuzio en octavo, que reproducían fielmente la cursiva humanística. Eran ediciones de los clá sicos que incluían textos completos en algunos cientos de páginas de pequeño formato. Servían de estímulo no sólo para el pensamiento sino también paralaimaginación. La popularidad de tales ediciones premió el ingenio de Manuzio,11 pues complementaron las ediciones en cuarto. La edición en octavo, que es el libro de bolsillo, fue el ariete renacentista que derribó las pesadas ediciones en folio medievales. A diferencia de estas últimas, las ediciones aldinas, aunque contenían prólogos, prescindían totalmente de notas y de comentarios, aspecto imprescindible en las ediciones medievales. Esos libros de bolsillo eran dúctiles y fácilmente manejables y transportables: a través de ellos la racionalidad se impregnaba de sólida levedad para expandirse por doquier y ejercer su efecto crítico. Las ediciones en octavo consolidaron los logros de la imprenta y acabaron por dibujar en filigrana los contornos de la galaxia de $\mathrm{G}$ utenberg. Asimismo esas ediciones fueron lo que estimuló una nueva práctica de la lectura que rompía con la práctica de la lectura medieval, fundada en un conjunto de textos canónicos avalados por la tradición y la autoridad; y que los intérpretes oficiales convirtieron en el basamento del castillo escolástico. Pero tales textos no eran considerados como obras de personas sino como conjuntos impersonales de proposiciones, que a su vez eran fatigosos debido a las infinitas introducciones, comentarios, interpretaciones, glosas y tratados anejos. La lectura de los humanistas comenzó cuestionando esa laberíntica parafernalia que ahogaba el texto

11 Cfr. Paul F G rendler y Julia Cartwright. AldbManuzio, episodiospara unabiografía, México, Editorial Aldus, 2000. 
hasta hacerlo desaparecer, y para evitar las incansables hordas de escoliastas prefirieron leer directamente a los autores clásicos. Además, al disponer de mayor cantidad de ediciones que contenían el texto original depurado de notas y comentarios, pudieron cotejarlos y con ello criticarlos; de esta forma reafirmaban la autonomía de la racionalidad. Esto finalmente le confiere solidez al contenido de la mente de las colectividades y los individuos que la ponen en marcha, y de paso los hace poseedores de un espacio real, físico, desde el que interactúan con las demás colectividades y entre ellos teteáttee es decir, también sensorialmente, condición que posibilita la constitución del espacio público para que el libro y la lectura se convierten en catalizadores.

D urante el otoño de la Edad Media se inicia el largo proceso de privatización de las sociedades occidentales que culminó en el siglo XVIII. La gradual descomposición del orden medieval que dio paso a las complejas estructuras políticas de los Estados modernos, conllevó también la sustracción de los individuos delas exigencias y de la vigilancia que ejercía el aparato de control y de administración estatal. En proporción directa con el fortalecimiento del poder del monarca y de la expansión del cuerpo burocrático, que penetran hasta el último resquicio de la colectividad, se da el contramovimiento que hace que los particulares busquen sustraerse a la esfera pública del Estado y constituir un nuevo espacio público fundado en la comunicación sensorial y racional entre personas privadas, y que tiene como principio la igualdad natural entre sus distintos miembros. Semejante esfera pública no conoce la jerarquización social puesto que, como señala Roger Chartier, se apoya "En el intercambio de los juicios, en el ejercicio de la crítica, en la confrontación de las opiniones, se establece aprioi una igualdad entre los individuos que sólo distingue la mayor o menor evidencia y coherencia de los argumentos esgrimidos." 12 Esto significa que tal espacio es público y ha sido determinado por el ejercicio de la racionalidad entre individuos semejantes en su autonomía y libertad, lo que, por otra parte, entraña la simiente de la democracia moderna. Pero esta nueva esfera pública se encuentra cruzada por dos movimientos contradictorios: ampliacióny exdusión En el primero los impresos crean una comunidad crítica que incluye a lectores, oyentes y espectadores privados cuya posesión de bienes y cultura les permite dominar el discurso de la racionalidad; por el contrario, el segundo implica que bienes y cultura no son patrimonio de todos, el debate político que se ventila en este espacio público está alejado de la mayoría que carece de los conocimientos que le permitirían la acción racional pública. El refuerzo argumentativo (ideológico) de los ilustrados del siglo XVIII es que el pueblo, debido a su incapacidad racional de participación debe ser representado en esa esfera pública, por lo que los hombres ilustrados se presentan como sus tutores. Esta exclusión es una limitante de los logros que la colectividad alcanza a través del espacio público y por ello mismo significa que el ideal que dio origen al espacio

12 Roger Chartier. Espaciopúblico cúticaydesacralizacónend sigoXV III. Loscrígenesailturalesdela revdur dónfrancesa, Barcelona, Gedisa, 1995, p. 34. 
público es un proyecto vivo y aún por realizar de manera completa, aunque en el pre sente sea desviado por las sociedades electrónicas globalizadas, que convierten el contenido de ese espacio público en pura forma y ahondan la exclusión: el medio es el mensaje.

El libro y la lectura son factor primordial en la constitución del espacio público, de hecho son los responsables de darle densidad, solidez y concreción; son ellos los que posibilitan la espacialidad del espacio público. La lectura de textos impresos permite fijar espacialmente las formas de relación pública, pues en la medida que hay una mayor cantidad de libros disponibles gracias alaimprenta y que eso libros están más o menos homogenizados por un patrón de impresión, se da una amplia y unificada difusión del pensamiento, las ideas u opiniones en ellos contenidos, lo cual redunda en la conformación de la sociedad lectora dirigida por el orden de los libros. La sociedad lectora no debe entenderse sólo como aquella compuesta por quienes saben leer, sino como aquella que está determinada por la circulación concatenadora de los impresos y que, por lo tanto, también determina la vida de quienes no saben leer. El orden de los libros es un orden de relaciones, cuyo eje relacional es precisamente el libro. ${ }^{13}$ La fijación de relaciones entre los individuos integrantes de la sociedad lectora que lleva a cabo el orden de los libros es realizada en y desde un espacio objetivo e histórico. El libro circula entre los lectores a través del tiempo, pero esa circulación temporal gradualmente se transfigura en espacialidad, como lo observó con agudeza Carla Hesse cuando dice:

El libro es una forma lenta de intercambio. Es un modo de temporalidad que concibe la comunicación pública no como acción sino como reflexión. D e hecho, el libro sirve precisamente para retrasar la acción, para crear un espacio para la reflexión y el debate. El libro, como reconoció Marcel Proust, es un fulcro que crea espacio a partir del tiempo. ${ }^{14}$

Para que el ámbito interrelacional del espacio público no se difumine en el puro movimiento de sus integrantes, el libro ralentiza el movimiento y con ello le da anclaje espacial, lo que en sentido textual convierte al espacio público en un lugar espacial. Contar con una precisa ubicación objetiva para este espacio hace que sus integrantes obtengan la garantía para el debate y la reflexión igualitaria. Lo que termina por darle densidad a los contenidos de la mente, a la par que dota de solidez al contenido cohesionador social del espacio público: legitima el carácter objetivo de sus miembros, y todo esto desde el marco de la espacialidad histórica. De hecho puede decirse que, por estas circunstancias, es el siglo XVIII el momento en que la galaxia de Gutenberg alcanza su fase definitoria del proceso de darle solidez al contenido y,

13 Para una mayor explicación sobre esta concepción de la sociedad lectora y el orden de los libros véase: H. G . Alfaro López. "Los usos de la lectura y la representación cultural: elementos para una teoría de la lectura” en Varios, Lainformadónend inidodelaeadectrónica. Infomadón, sociedadyteendo ǵa, México, UNAM-CUIB, 1998.

14 C. Hesse. "Los libros en el tiempo" en Nunberg, G eoffrey (comp.), El futurodd libra ¿Estomatará @o?, Op at, p. 32. 
por tanto, primacía sobre la forma. ${ }^{15}$ Solidez lograda bajo el signo de la espacialidad, cuyos factores determinativos fueron el libro y la lectura.

El libro impreso como producto y productor de un modelo liberal de vida pública que preservala objetividad de laindividualidad dentro de una comunidad intelectual, fue resultado de la tecnología de la imprenta, tecnología que conforme se desarrollaba hizo del libro un objeto privilegiado que fue perfeccionando su manufactura. Mas el libro acabó por ser desbordado por el propio avance tecnológico. Ese rebasamiento fue dándose de manera paulatina a lo largo del siglo XX, pero se aceleró en las últimas décadas. El año emblemático que justificatal aceleración tecnológica es 1995, fecha que además señala el tránsito del capitalismo hacia otra de sus configuraciones: la sociedad de la información, desembocadura consecuente de la racionalidad instrumental que embrida el desarrollo tecnológico. En aquel año se reúne en Bruselas el consejo deministros de las principalesnacionesindustrializadas para perfilar oficialmente lavía que debe conducir a la instauración de la sociedad de la información. Para ello se otorgaron toda clase de apoyos y no se escatimaron los subsidios, que tenían como finalidad la comercialización completa de los medios de información y la estructuración de redes globales. Todo esto da lugar a una nueva fuente de riqueza social: la venta de información y de diversión de masas a través de los medios electrónicos. La información se transmuta en simple mercancía a la que tienen acceso sólo aquellos que la pueden pagar. A través de la tecnologíainformática se da la alquimia que desvanece todo lo sólido en luz; lo que asimismo viene a significar el triunfo de la forma sobre el contenido: themediumis themessage

La sociedad de la información se erige sobre una reconstitución de las categorías de la experiencia concreta, que se da en el espacio-tiempo; reconstitución que en el fondo significa un privilegiamiento del tiempo sobre el espacio. Tiempo que realiza el ideal del capitalismo: mayor eficiencia y productividad. Esta reformulación del tiempo deja de lado su concepción como un continumy lo segmenta, institucionalizándolo laboralmente, a través del tiempo a corto plazo. Al quedar fragmentado el tiempo por el corto plazo pierde densidad (solidez) y se asemeja a un líquido que escapa de las manos, de la vida así segmentada de los individuos. ${ }^{16}$ Tiempo líquido que

15 'El sistema literario modamo la 'modernizada civilización del libro' surgida de las revoluciones democráticas del siglo XVIII, representa una visión de la vida cultural que abarca los ideales del individuo autónomo, que se crea y se gobierna a sí mismo y que posee algunas propiedades, un acceso universal al conocimiento y la garantía del debatey la reflexión públicay prudentes”. Ibid, p. 33.

16 El sociólogo Richard Sennett ha realizado un penetrante estudio sobre el devastador efecto que provoca la concepción del tiempo a corto plazo en los trabajadores de los países desarrollados, los cuales funcionan bajo la estructura laboral en forma de red, propia de la nueva fase tecnificada del capitalismo. A ese efecto devastador lo denomina conosónda caráder, es decir la pérdida del contenido del carácter individual en aras del predominio de la nueva forma laboral: el medio es el mensaje. "Una razón para esta superficialidad degradante es la desorganización del tiempo. La flecha del tiempo se rompe; no tiene una trayectoria en una economía política constantemente reconvertida, que odia la rutina y programa a corto plazo. La gente siente la falta de relaciones humanas sostenidas y propósitos duraderos". Laconosióndd caráder. Lasconseuenias persanalesdd trabajoend nuevoca pitalism, Barcelona, Anagrama, 2000, p. 103. 
fluye inasible para expirar un momento después. Liquidez que rápidamente desvanece el mensaje para sólo dejar la vacuidad luminosa del medio electrónico.

Puede decirse que en gran medida el efecto alucinatorio que ejerce la televisión sobre el público se debe a que por las mínimas coordenadas de la pantalla fluye el tiempo con mayor liquidez, fue quizá eso lo que impactó a McLuhan y de donde dedujo la capacidad del medio frío para unificar los sentidos humanos. Pero lo que no consideró fue que el tiempo líquido de la pantalla disgrega el contenido de los sentidos. Las imágenes fluyen a gran velocidad en la conciencia del telespectador sin darle el respiro necesario para procesarlas. Todos los sentidos se unifican y están alerta para captar las imágenes que le asesta el televisor, pero la mente del espectador es conducida al pasmo, sus mecanismos de interpretación global y crítica son paulatinamente desactivados, y su lectura de las imágenes sólo resbala por la superficie. Además, el incontenido flujo de imágenes obliga a que se les preste toda la atención, lo que implica restársela al entorno. El otro comienza a desvanecerse del horizonte individual. Volverá a entrar en el foco visual del telespectador cuando sea convertido en imagen, cuando sea parte del medio frío y, en cuanto tal, pura forma: el medio es el mensaje.

McLuhan no alcanzó a ver el despegue de la tecnología computarizada, pero observó su prefiguración con la televisión, en la que ya se anunciaban las características definitorias del medio frío que marcó con su impronta el fin del siglo XX, y que está llamado a dirigir el rumbo de la centuria naciente. Esto, que conjeturablemente hubiera confirmado a McLuhan en su papel de profeta, sin embargo más bien lo ratifica como uno de los intelectuales más perceptivos para codificar, mitificándolas, las fuerzas tendencias y contradicciones de su propia época histórica. Y esto sin demasiado complejas elaboraciones discursivas, al grado de que la misma estructura formal de sus libros se corresponde ceñidamente con la forma de una centuria signada por la desintegración de sus contenidos.

La red de computación terminó por envolver a las estructuras sociales y a la vida cotidiana de amplios sectores de individuos, porlo que acabó porinfisionar al libro y a la lectura. Se ha convertido en un nuevo soporte de los textos y dado lugaral llamado libro electrónico, que necesariamente conlleva una práctica de la lectura adecuada a tal soporte y trastoca a fondo los paradigmas en que se habían desenvuelto históricamente el libro y la lectura desde la invención de la imprenta. El medio electrónico está determinado por la velocidad de la luz, que al convertirse en texto que pasa por la pantalla se transfigura en tiempo líquido. En la pantalla de la computadora se despliega un texto que es desestructurado en temporalidades a corto plazo y que puede ser segmentado, recompuesto o convertido en un simple rompecabezas para armar o desarmar, a semejanza del libro Lagalaxia Gutenberg Factor primordial que actúa sobre la desestructuración del texto es que sobre él gravita la disponibilidad de ingentes cantidades de información, de textos. Lo que resulta en una práctica de la lectura discontinua, zigzagueante, apremiada por el flujo del tiempo líquido que arrastra los textos para esparcirlos en el vertedero del ciberespacio. Esto hace 
que el texto electrónico nos enfrente al agobio que surge de la posibilidad de disociar una obra o texto específico de un productor individual, o de que el autor pierda su individualidad e incluso también el lector. Esto significa que se abre la posibilidad para desaparecer el sentido de uno mismo y de la sociabilidad derivada del espacio público, en la medida en que la comunicación vía Internet posibilita el acercamiento virtual de lo lejano y que aleja a lo real inmediato; en otras palabras, en la medida en que los individuos objetivos se aislan de los demás individuos para mediar sus relaciones con la computadora, fracturan el espacio público, que desde el siglo XVIII ha sido factor decisivo para el desenvolvimiento del proyecto civilizatorio occidental. Asimismo, el tiempo líquido que permite desestructurar la organización de los textos y con ello difuminar su contenido, acaba también por cerrar esa otra línea de tensión que desde el Renacimiento fue conformadora de Occidente: el humanismo racionalista; para dar lugar al diálogo distante entre entes virtuales, diálogo deshumanizado y balbuceante en el que la racionalidad pierde solidez.

Los lectores del texto electrónico se desobjetivizan para gradualmente convertirse en subjetividades postmodernas que se componen y recomponen continua y espontáneamente en un espacio virtual, que ha consumido al espacio objetivo que le daba realidad al espacio público. Esto asimismo fue consecuencia de que mientras el libro impreso crea espacio a partir del tiempo, con el libro electrónico se da una completa inversión en la que se crea tiempo a partir del espacio. La espacialidad objetiva de la galaxia $\mathrm{G}$ utenberg se desvanece en el tiempo líquido de la era electrónica. El ocaso de la galaxia $G$ utenberg decretado por McLuhan viene a representar en última instancia la crisis del libro y de la lectura tal como hasta ahora había sido aquél producido y ésta practicada. Empero para que el sentido profundo de lo que eso entraña se revele es menester remitirnos al significado etimológico de la propia palabra crisis, proveniente del verbo griego kńnėnque significa separar, decidir, y del cual deriva el sustantivo knisisque quiere decir: "punto decisivo", por eso cuando se hace referencia a una crisis ello no significa aniquilación, ni mucho menos marca un punto final sino el punto decisivo: el punto fronterizo que separa una trayectoria previa de la que se avecina.

El siglo XX representa un punto de inflexión en la historia de occidente y, por ende, es una centuria en crisis, lo cual se refleja en la crisis del libro y la lectura. La crisis general de la centuria expresa el punto de separación entre dos configuraciones del capitalismo: la sociedad industrial y la nueva sociedad de la información. La configuración anterior se articulaba todavía con una concepción del tiemposáida que le daba solidez ala existencia humana. El tiempo sólido delos días y las pasiones, de los rituales y las transgresiones, de las claudicaciones y los logros; tiempo que dotaba de contenido y de sentido a la existencia cotidiana de los individuos. Mientras que la sociedad informatizada fluye en el tiempo líquido, cuyo vértigo tiene la notable virtud de homogeneizar el contenido de la existencia supeditándola a la forma globalizada y virtual. Todo esto, en resumen, encuentra eco en la crisis por la que atraviesan el libro y la lectura; así, mientras que con anterioridad el libro era claramente un objeto 
sensorial, vehículo creador de la razón cuya lectura permitía conformar el lenguaje y la memoria - que eran condición de posibilidad del humanismo y el espacio público donde los individuos se encontraban corpórea y racionalmente frente a frente, esto es, como seres humanos- , ahora el libro electrónico se convierte en un instrumento que obnubila la comunicación sensorial, cuya lectura conduce a la deconstrucción del lenguajey al bloqueo de la memoriay, con ello, de la conciencia histórica. Estees el punto fronterizo que manifiesta la crisis del libro y la lectura, sin embargo la frontera es un punto intermedio y adelante se anuncia el camino que, en realidad, será el decisivo. Y es deseable que ese camino decisivo, que por hoy parece lejano, entrañe la conservación de lo mejor que ofrece la tecnología electrónica, para que ésta sea guiada por lo mejor de la galaxia $\mathrm{G}$ utenberg, lo que entraña una reconstrucción de los contenidos en todos los niveles: social, individual, mental y de la comunicación. En suma ello implicaría la recuperación de lo plenamente humano, que es finalmente el contenido de los contenidos, ${ }^{17}$ y que el siglo XX emprendió la hazaña de supeditarlo a la forma mecánica y cibernética. Recuperar el contenido humano en el fondo vendría a significar nuevamente, y a restablecer que $\mathrm{A}$ contenidbes $\mathrm{A}$ mensaje

\section{A PÉNDICE DOCUMENTAL}

\section{El otro rostro del profeta}

Hacia mediados del siglo XX Marshall McLuhan, profeta de tecnólogos y comunicólogos, en su best seller LagalaxiadeGutenberg Génesisdd homotypogaphiauslanzó la terrible profecía en la que decretaba el cercano fin de los librosy, por extensión, de toda la cultura fundada en ellos. Pero no puede dejar de señalarse, en descargo de McLuhan, que su libro LagalaxiadeGutenbeges veladamente una elegía a los libros, a la sociedad tipográfica en la que él creció y que lo formó intelectualmente; un lamento por un mundo amado cuyo fin se testifica con dolor. No podía ser menos en un autor que se había nutrido de humanismo, pero queal dejarse seducir por las (en ese entonces nuevas) tecnologías de la información optó por convertirse en el cantor de un pasado en vías de extinción y en el jubiloso profeta de un futuro en el que el homo typogaphiausha desaparecido. Y eso que él ya no alcanzó a ver: el auge y triunfo de la tecnologíainformática dela computación, hubiera sido la confirmación, incluso con creces, de su apocalíptica visión futurista. Sin embargo, suponiendo que McLuhan hubiera podido sentarse frente a la pantalla de una computadora personal, y entregarse a la estupefaciente experiencia de viajar durante horas por el ciberespacio teniendo a su disposición toda la información acumulada durante milenios por el gé nero humano 0, más particularmente, toda la información disponible sobre su querido Shakespeare, probablemente hubiera concluido en un primer momento que

17 Por esta razón puede decirse que el ser humano es el contenido del mundo. El filósofo Eugenio Trías ha expresado esto diciendo que los seres humanos somos el límite y la frontera del mundo. 
fue necesario acabar con las limitantes que impone el libro, para que pudiera darse la utopía que permite la difusión masiva y democrática del conocimiento. Mas a un hombre con su visionaria inteligencia no se le hubiera escapado el hecho de que en el fondo algo no anda bien con la informática computarizada, porque los "vestigios" de la cultura tipográfica sobreviven dentro de ella. Así, en un segundo momento hubiera quizá concluido que la fragilidad de los libros tiene una fuerza de sobrevivencia que se nutre de la historia y que la hace perseverar en su continuidad. Perseverancia que incluso les sirve como argumento a todos aquellos remisos a esta nueva tecnología para tronar contra ella en aras de defender al homotypogaphias como la escritora Annie Proloux, que lanza su grito de guerra cuando dice que la autopista de la información tendida por la Internet sólo sirve para transmitir "boletines de anuncios sobre asuntos esotéricos, obras de referencia, listados y noticias, es decir, información utilitaria, eficacia a través de los cables. Nadie va a sentarse a leer una novela en una ridícula pantallita. Nunca".

D e haber ecuchado McLuhan esta opinión de Annie Proloux probablemente su comentario hubiera sido en el tenor de que la susodicha escritora lo único que demuestra con ello es que pertenece a la casta de los últimos mo hicanos tipográficos, y continuaría su argumentación diciendo que lo que esto deja en claro es que más que hablar del fin de instituciones culturales, como en este caso el libro, debe hablarse de convivencias, independencias, fusiones, tensionesy metamorfosis, creadas a partiry en relación con las nuevas tecnologías. E s conjeturable que en el fondo, más allá de su disfraz de profeta, esto es lo que más le hubiera agradado a McLuhan.

\section{Espacio público y tecnología}

Cada avance científico conlleva una cauda de bondades y destrucción para los seres humanos. Luz y oscuridad de una necesidad social. Contra la marea apologética que sólo quiere mirar la luz resulta necesario también ver el lado oculto para pensarlo a fondo; de no contemplar esta parte se corre el riesgo de que la luz literalmente nos deje ciegos, lo que podría hacer a la tecnología aún más deshumanizadora. O bstinarse en querer ver sólo un lado es una variante de la ceguera intelectual. El área tecnológica que en la actualidad es mayormente objeto de una desmesurada apología que acalla la crítica, es la concerniente a la informática. El lugar común que se esgrime sobre las bondades de la tecnología informática es la disponibilidad, en cualquier momento y en cualquier lugar, de toda la información que se desee sobre el tema que sea; lo que viene aparejado con una aceleración de la velocidad en la comunicación, que a su vez permite disminuir las distancias geográficas entre los individuos. Todo ello redunda en ahorro de tiempo y en agilidad en las operaciones mercantiles pero, más aún, es la palanca de apoyo para expandiry consolidar el proceso de globalización. De hecho hablar de mundo globalizado implica, por necesidad, hablar de un mundo interconectado por la tecnología de la información. Sin embargo, este es sólo el aspecto que se desea considerar benéfico; el aspecto negativo no es 
algo que ande rumoreando en las catacumbas de semejante tecnología, de hecho está presente en su misma dimensión benéfica. Pero cuando sellega a señalar la parte negativa habitualmente se resbala en la superficie del problema: acentuar lo negativo a partir de lo puramente superficial refuerza el aspecto positivo y dentro deél se hace más destructiva su otra parte. La oscuridad se vuelve más densa cuando se la hace pasar por penumbra.

Cuando se dice, por ejemplo, que Internet fomenta las relaciones entre los individuos a larga distancia a cambio de bloquear las relaciones a corta distancia, no se está incidiendo en el problema de fondo. Es cierto que la forma como se despliega la tecnología cibernética tiende a empujar a los individuos a encerrarse dentro de sí mismos o, más exactamente, a encerrarse con su aparato electrónico (p. ej. computadora) y rehuir el contacto con los demás seres humanos, lo cual está muy cerca de ser una variante del autismo. Visto sólo así, este escorzo del lado oscuro de la tecnología informática arroja como conclusión que fuera de algunas perturbaciones psicológicas de la personalidad todo está bien, e incluso que tales perturbaciones son insignificantes comparadas con las grandiosas y liberadoras bondades que ofrece. Pero cuando buscamos contemplar a mayor profundidad comprendemos que ese autismo encierra una problemática en la que está en juego una de las vías que marcan la trayectoria histórica del mundo occidental.

D esde el final dela Edad Media surge una nueva concepción del hombre, que desemboca en la divinización que de él hace el Renacimiento: un ser autónomo, racional y libre. Paralelamente el ser humano va sustrayéndose de la esfera pública del poder para constituir la esfera de la vida privada. Para el siglo XVIII, esa esfera privada se ha constituido en el espacio privilegiado de la opinión pública política, base de la democracia moderna. Espacio público necesario para el intercambio de juicios y el ejercicio de la crítica, ámbito donde al confrontarse personalmente los individuos terminan por fomentar el uso de la racionalidad, poniendo de paso en marcha una sociedad más igualitaria que busca dejar atrás las jerarquías y desigualdades. Pero esto, entiéndase, a través del contacto humano inmediato (físico, emocional, racional); es decir, la comunicación sensorial, nada hay que acontezca en la mente que antes no haya pasado por los sentidos. A unque esta trayectoria histórica que conducea la democracia no se ha realizado de manera completa, la aspiración sigue viva; sin embargo una tecnología que desestructura las relaciones de presencia inmediata y racionalidad entre los hombres pone en grave riesgo la aspiración hacia una democracia real (no de formalismo mediático), pues la democracia es una forma de relación entre individuos, como diría Unamuno, de "carney hueso", no de entes virtuales. Es éste uno de los aspectos negativos sobre los que se debe reflexionar por lo que se refiere a la tecnología informativa.

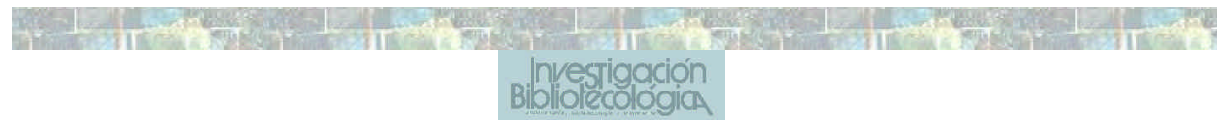

